In Cres. Vol. $4 N^{\circ} 1:$ pp. 185-192, 2013

\title{
TECNOLOGÍAS DE LA INFORMACIÓN Y LA COMUNICACIÓN INTEGRADAS A LOS PROCESOS EDUCATIVOS*
}

\author{
INFORMATION AND COMMUNICATION TECHNOLOGIES \\ INCORPORATED TO EDUCATIONAL PROCESSES
}

\author{
Anthony José Gomez Morales ${ }^{1}$
}

\begin{abstract}
RESUMEN
El presente artículo trata sobre la aplicación de las Tecnologías de la Información y la Comunicación, específicamente, las Tecnologías Web, al proceso educativo como una herramienta que favorezca el proceso de enseñanza-aprendizaje. Los objetivos fueron: 1) Introducir al lector en los conceptos claves de las Tecnologías de la Información y la Comunicación y las Tecnologías Web; 2) Incitar al lector a incorporarlas en la Educación; 3) Animar a reflexionar sobre las bases para el diseño, la producción y la evaluación de procesos de enseñanza-aprendizaje mediante nuevas tecnologías; 4) Presentar un conjunto de herramientas utilizadas en el contexto educativo actual.

PALABRAS CLAVE: Tecnología de la Información y la Comunicación, educación, herramientas educativas, Web 2.0, Blog, Wikis, aula virtual.
\end{abstract}

\section{ABSTRACT}

This article discusses the application of Information and Communication Technologies, specifically, Web Technologies to the educational process as a tool that promotes the teaching-learning process. The goals were: 1) To introduce the key concepts of Information and Communication Technologies and the Web; 2) To encourage the reader to incorporate them in Education; 3) To encourage reflection about the basis for the design, production and evaluation of teaching-learning processes through new technologies; 4) To present a set of tools used in the current educational context.

KEY WORDS: Information and Communication Technology, education, educational tools, Web 2.0, blogs, wikis, virtual classroom.

* Recibido: 20 de junio del 2013; aprobado: 30 de junio del 2013.

1 Ingeniero Informático. Postgrado en Dirección de Sistemas de Información-Universidad Oberta de Cataluña-Barcelona España. Maestría en Pedagogía Universitaria (e). Docente Universitario. 


\section{INTRODUCCIÓN}

Las Tecnologías de la Información y la Comunicación (TIC), especialmente las herramientas WEB, tienen cada vez una mayor presencia en la sociedad. El contexto educativo no es ajeno al impacto que las TIC están provocando en el ámbito educativo. Más aún, si consideramos que el actor principal en el proceso de enseñanza-aprendizaje es el alumno, en la actualidad las TIC toman mayor importancia por la denominada "generación Y", el estudiante digital, en el que la interactividad es su característica y que percibe de manera multimodal, que se desarrolla en la sociedad de la información y que demanda una mayor preparación por parte de los educadores. Por ello, desarrollar una educación actual exige considerar y asumir el rol preponderante que tienen las TIC. La actualización de conocimientos y capacidades de profesores y gestores es, al respecto, una demanda profesional, pero, también, una respuesta necesaria a la realidad en la que trabajan.

\section{TECNOLOGÍAS DE LA INFORMACIÓN Y LA COMUNICACIÓN}

Podríamos definir que son el conjunto de herramientas, equipos, programas, aplicaciones, redes y medios, que permiten la compilación, procesamiento, almacenamiento, transmisión de información, como: voz, datos, texto, video e imágenes. Las TIC constituyen el acontecimiento cultural y tecnológico de mayor alcance y expansión del último siglo y lo transcurrido del presente. Nuestro país no escapa a tal proceso de globalización y de la sociedad de la información, de acuerdo a los resultados de la Encuesta Nacional de Hogares(ENAHO 2011):

- El 25,2\% de los hogares del país tiene en sus hogares al menos una computadora.

- El 16,5\% de los hogares del país tienen internet. Respecto a lo registrado en similar trimestre del año 2010, se ha incrementado en 2,5 puntos porcentuales.

- El 36,5\% de la población de 6 y más años de edad hace uso de Internet.

- La población adolescente (12 a 18 años) y los jóvenes (19 a 24 años) son los que usan en mayor proporción internet $(61,6 \%$ y $61,7 \%$, respectivamente), seguido por los que tienen de 25 a 40 años, donde el $37,5 \%$ es usuaria de internet.

- Al analizar a los usuarios de internet, de acuerdo al nivel de educación alcanzado, se observa que la población con educación universitaria es 
la que en su mayoría $(81,6 \%)$ usa el internet, seguido por los que tienen educación superior no universitaria $(60,0 \%)$ y educación secundaria $(37,5 \%)$.

Este vertiginoso crecimiento ha ocurrido en los últimos años y, sin lugar a dudas, el mercado y su globalización han realizado un acelerado proceso de difusión y utilización de las TIC, especialmente de la Web.

\section{HERRAMIENTAS WEB}

Actualmente, casi todo está orientado a la Web y los procesos educativos no escapan a ello. Desde su aparición, la Web se constituyó en un recurso importante en el área educativa y, específicamente, para el desarrollo y auge de la educación a distancia. En este sentido, la aplicación de esta tecnología ha permitido el desarrollo de entornos que simulan aulas, laboratorios, sesiones de clases y hasta universidades completas. Estos ambientes son conocidos como entornos virtuales y permiten aumentar el alcance de su contraparte física. Esta fácil adaptación de tal tecnología, se debe a las siguientes características:

- No es necesario ser un especialista en informática para poder utilizarla. Son sumamente fáciles y están diseñadas para brindarnos guías y ayudas para su empleo por personas que no conocen mucho de informática y computación.

- Los contenidos (documentos) son dinámicos y pueden contar con gran variedad de elementos multimedia, tales como videos, fotografías, imágenes, música, y otros.

- Existen muchas herramientas que permiten que el público en general pueda participar en la construcción de los contenidos del sitio. Se ha borrado la línea de división entre los autores (llamados también productores) y los lectores de esa información (llamados también consumidores). Se ha acuñado un nuevo término: prosumidores, para denotar que son productores y consumidores de contenidos, al mismo tiempo.

\section{BASES PARA EL DISEÑO, LA PRODUCCIÓN Y LA EVALUACIÓN DEL PROCESO DE ENSEÑANZA-APRENDIZAJE MEDIANTE NUEVAS TECNOLOGÍAS}

Si consideramos la educación como una ciencia de diseño, enfatizando su orientación interdisciplinaria y orientada a problemas, entonces el diseño representa un medio de mejorar las situaciones existentes. Consideramos las bases 
relacionadas con el diseño, tales como las teorías del aprendizaje, teorías del currículo, de la instrucción, de la comunicación, del desarrollo de los sistemas de información, entre otros. Si el diseño instructivo debe ofrecer una guía de cómo ayudar a las personas a aprender y a desarrollarse mejor, entonces, conocer sus fundamentos, procesos y principios básicos que lo orientan, ayudará a comprender los procesos de enseñanza-aprendizaje que se desarrollan en entornos propiciados por las TIC. Según Cabero (2007) debemos considerar:

\section{DISEÑO DE PROCESOS ENSEÑANZA-APRENDIZAJE MEDIANTE TIC}

Los entornos de aprendizaje construido con la ayuda de las TIC se componen de recursos, hardware y software, utilizados en la enseñanza (ejemplo: aulas de computadores con acceso a Internet), servicios y recursos descentralizados ofrecidos a través de la red de información (por ejemplo páginas web, como recursos y herramientas de aprendizaje). Una metáfora de un lugar de estudio (espacio virtual) creado con ayuda de las TIC, en la que se pretende ofrecer las mismas actividades que en un lugar concreto.

\section{FUNDAMENTOS DEL DISEÑO}

Los fundamentos para el diseño de medios didácticos se hallan vinculados de manera indisoluble con las fuentes de la tecnología educativa, las que son tres:

a) Perspectiva psicopedagógica: La psicología conductista, la psicología cognitiva con la toría del aprendizaje significativo de Ausbel; aprendizaje por descubrimiento o teoría de Bruner; epistemología genética de Piagety la perspectiva evolutiva.

b) Teoría de la comunicación: Transmisión, almacenamiento y procesamiento de la información.

c) Teoría general de sistemas: fases generales: Definición del problema, análisis (para generar alternativas), selección y síntesis de una solución óptima, puesta en práctica de manera controlada, evaluación y posible revisión

\section{PROCESO DE DISEÑO}

Algunos de los aspectos más significativos de cada una de las etapas:

Fase de diseño. Análisis de la situación, que incluye aspectos como identificación del contenido sobre el que tratará el material; delimitación de la audiencia; identificación de las destrezas didácticas a emplear; equipamiento disponi- 
ble y capacidades y limitaciones del mismo; existencia de materiales similares, entre otros.

Fase de producción. Desarrollo del producto, que incluye las decisiones de la fase anterior (contenido, extensión, aspecto y metodología del material), que son puestas en práctica y cuyo resultado es ya un producto.

\section{CRITERIOS DE EVALUACIÓN}

La variedad de procedimientos relacionados con los medios didácticos:

- Evaluación prospectiva o evaluación relativa al contexto (context evaluation). Trata de evaluar los medios mejor adaptados a un determinado proyecto pedagógico.

- La evaluación del producto (input evaluation). Valorar la calidad científica y técnica de un material didáctico antes de su difusión.

- Evaluación para la selección de medios. Procesos valorativos encaminados a proporcionar criterios a los profesores usuarios.

- Evaluación en la circulación (output evaluation). La que se realiza después de haberse utilizado el medio.

\section{VENTAJAS DE INTEGRAR LAS TECNOLOGÍAS WEB EN LA EDUCACIÓN}

La tecnología Web permite una cantidad de experiencias educativas nuevas, como visitas a museos de arte y de ciencias, acceso a laboratorios virtuales, viajes virtuales a ciudades o regiones remotas, utilización de software educativo interactivo, etc. Además, las TIC con toda la gama de herramientas de hardware y software que contienen, usadas para potenciarla, facilitan la creación de ambientes de aprendizaje enriquecidos, que se adaptan a modernas estrategias de aprendizaje, con excelentes resultados en el desarrollo de las habilidades cognitivas de niños y jóvenes, en las áreas tradicionales del currículo.

Podemos destacar las siguientes ventajas de aplicarlas en la educación:

a) Aprovechar la gran cantidad de información o contenidos de conocimiento disponibles en Internet.

b) Actualizar, transformar y enriquecer los ambientes de aprendizaje en que se educan los niños y jóvenes.

c) Desarrollar las competencias necesarias para desenvolverse con efectividad en el Siglo XXI. 


\section{HERRAMIENTAS DE LA TECNOLOGÍA WEB}

Estas herramientas permiten que cualquier usuario, que tenga acceso a Internet, pueda crear recursos educativos como sitios web y contenidos de una forma rápida y sencilla. Se destacan herramientas como los Blogs, Wikis, entornos virtuales de aprendizaje:

- Blogs. Es un sitio web, periódicamente actualizado, que recopila, cronológicamente, textos o artículos de uno o varios autores, apareciendo primero el más reciente, donde el autor conserva siempre la libertad de dejar publicado lo que crea pertinente. Podemos crear uno, completamente gratis en http://www.blogger.com/.

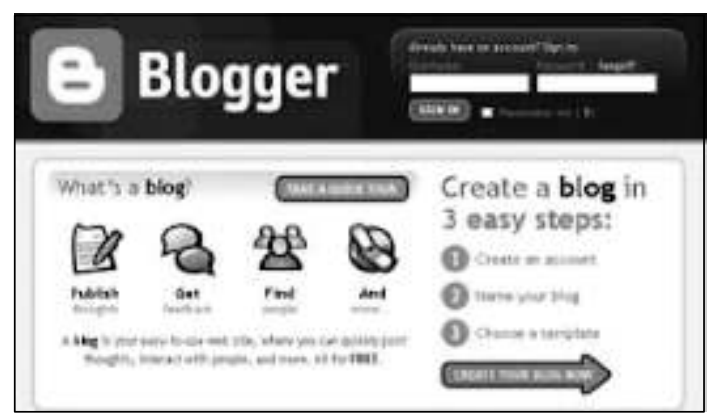

Figura 1. Interface de Blogger. Fuente: (URL 1).

- Wikis. Un wiki o una wiki es un sitio web cuyas páginas pueden ser editadas por múltiples voluntarios a través del navegador web. Los usuarios pueden crear, modificar o borrar un mismo texto que comparten. Los textos o «páginas wiki» tienen títulos únicos. Si se escribe el título de una «página wiki» en algún lugar del wiki entre dobles corchetes, esta palabra se convierte en un «enlace web» a la página wiki. Podemos crear uno completamente gratis en http://www. wikispaces.com/.

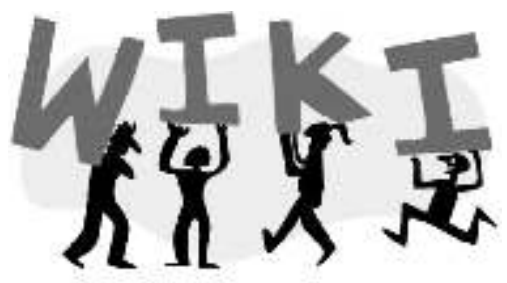

Figura 2. Logo de las Wiki. Fuente: (URL 2). 
- Entornos virtuales de aprendizaje. Un entorno virtual de aprendizaje es un software con accesos restringidos, concebido y diseñado para que las personas desarrollen procesos de incorporación de habilidades y saberes; por ejemplo, un Aula virtual.

- Aula virtual. Dentro del entorno de aprendizaje, consta de una plataforma o software, a través del cual, el computador permite la facilidad de dictar las actividades en clases, de igual forma, permite el desarrollo de las actividades de enseñanza y aprendizaje habituales que se requiere para obtener una buena educación. A través de ese entorno, el alumno puede acceder y desarrollar una serie de acciones que son propias de un proceso de enseñanza presencial, tales como conversar, leer documentos, realizar ejercicios, formular preguntas al docente, trabajar en equipo, etc. La principal aplicación para la gestión de estas herramientas es Moodle: http://www moodle.org/.

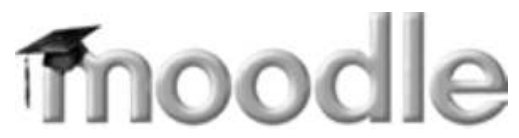

Figura 3. Logo de Moodle. Fuente: (URL 3).

\section{CONCLUSIONES}

La tecnología Web es un medio o un conjunto de herramientas, que no resuelven por sí mismas ningún problema básico de aprendizaje si no se las utiliza en función de un enfoque pedagógico claro, estableciendo un marco de referencia que tenga en cuenta la naturaleza y las metas del hecho educativo, determinar las variables que intervienen en la situación de enseñanza-aprendizaje y seleccionar las modalidades apropiadas de incorporación.

Se trata de diseñar, implementar y evaluar proyectos pedagógicos que estimulen la valoración y asimilación constructiva de las innovaciones tecnológicas. Las tecnologías Web serán valiosas, en tanto y en cuanto, sirvan para innovar y mejorar los principales procesos de la educación superior.

La aplicación de las tecnologías Web en el contexto de la educación, requiere el cumplimiento de ciertas condiciones: además de la disponibilidad de infraestructura informática apropiada, el desarrollo de metodologías de trabajo que incluyan el aprovechamiento de las posibilidades de las TIC, con la formación y capacitación del personal docente y no docente. 


\section{BIBLIOGRAFÍA CONSULTADA}

AgUADED, J. \& CABERO, J. (2002). Educar en red: Internet como recurso para la educación. Málaga, Aljibe.

Alonso, C. \& GAllego, D. (2002). Tecnologías de la información y la comunicación, Revista de Educación, 329, 181-201.

BAÑos SANCHO, J. (2008). Entorno Virtual de Aprendizaje, IES Satafi (Getafe).

Cabero Almenara, J. (2007). Nuevas Tecnologías Aplicadas A La Educación. McGraw-Hill.

CoBo Romaní, C. y PARdo KuKLINSKI, H. (2008). Planeta Web 2.0 Inteligencia Colectiva o Medios Fast Food, Grup de Recerca d'Interaccions Digitals, Universitat de Vic, Web oficial:www.planetaweb2.net.

ENAHO (2011). Encuesta Nacional de Hogares - INEI, http://www.inei.gob.pe/web/Boletin/Attach/ 13382.pdf.

FreIRE, J. (2008). La Gran guía de los blogs 2008, Retos y Oportunidades de la web 2.0 para las Universidades. Editorial El Cobre, 2008.

SALINAS, J. (2004). La integración de las TIC en las instituciones de educación superior como proyectos de innovación educativa. Conferencia. I Congreso de Educación mediada con Tecnologías. "La innovación Pedagógica con el uso de las Tecnologías de la Información y Comunicación". Recuperado el: 15 de Marzo de 2009 del sitio web de Grupo de Tecnología Educativa - Universitat de les Illes Balears http://gte.uib.es/castellan/pages/publictodas.htm.

SANGRÀ, A; GonZÁLEZ, M. (2004). El profesorado universitario y las TIC: redefinir roles y competencias. En: Sangrà, A; González, M. (2004). (Coords). La transformación de las universidades a través de las TIC: discursos y prácticas. Barcelona: UOC.

URL 1: http://www.blogger.com/

URL 2: http://www.wikispaces.com/

URL 3: http://www.moodle.org/ 